\title{
Evaluation of Faith Based Program On Attention- Deficit/Hyperactivity Disorder Symptoms in Young Children: A Randomized Controlled Trial
}

\author{
Rajubhai Popat Odedra1, Buddhatmananda Saraswati², Divya Gaur ${ }^{3}$ \\ NMP Medical Research Institute
}

\begin{abstract}
Attention Deficit Hyperactivity Disorder (ADHD) is a complex condition affecting children worldwide. In India, prevalence found to be $11.32 \%$ in primary school. Previous studies explored the effect of faith based arsha vidya program on elderly and disadvantaged children, but no study has been conducted to evaluate the effect of faith-based intervention on ADHD. Present study was undertaken for ADHD-risk children $(n=94)$ aged 8-12 years. Intervention consisted of 60 mints group practices, Vedic chants for 20, relaxation for 10 mints and 30 mints with Seva (service in the center). Children were assessed before and after the 3 months of intervention. Outcome measures were parent ratings of ADHD symptoms, behavior, mood, attitude and understanding toward peers.

Post data included 90 parents. AT the end of intervention, parents reported significant decrease in ADHD symptoms: $\mathrm{p}<.001$; oppositional symptoms: $\mathrm{p}<.001$; mood symptoms; $\mathrm{p}<0.01$. Parents reported better behavior towards peers but that did not reach significance levels.

To our knowledge, this is the first randomized trial to address faith-based intervention for an ADHD-risk sample. This study provides significant evidence on the beneficial effect of faithbased program on at-risk ADHD Children.
\end{abstract}

Keywords: ADHD, Children, Faith based intervention 